\title{
A unified model for estimating the in-situ small strain shear modulus of clays, silts, sands, and gravels
}

\author{
Brian D. Carlton ${ }^{\mathrm{a}, 1}$, Juan M. Pestana ${ }^{\mathrm{b}}$ \\ ${ }^{a}$ University of California, Berkeley, CA 94720, USA; brian.carlton@ngi.no \\ ${ }^{\mathrm{b}}$ University of California, Berkeley, CA 94720, USA; jmpestana@berkeley.edu
}

\begin{abstract}
This paper proposes a unified model to estimate the in-situ small strain shear modulus of clays, silts, sands, and gravels based on commonly available index properties of soils. We developed a model to predict the laboratory small strain shear modulus $\left(\mathrm{G}_{\mathrm{max}, \mathrm{lab}}\right)$ using a mixed effects regression of a database that contains 1680 tests on 331 different soils. The proposed model includes the effect of void ratio, effective confining stress and overconsolidation ratio as well as plasticity index, fines content, and coefficient of uniformity. We compiled a second database to estimate the in-situ small strain shear modulus ( $G_{\max , \text { in-situ }}$ ) from laboratory ( $\left.G_{\text {max,lab}}\right)$ measurements. This study validated and compared the resulting model with other existing models using a third database of measured $\mathrm{G}_{\max , i n-s i t u}$ values. The residuals of the proposed model had a mean and median closer to zero and the smallest standard deviation of all the models considered. By including a statistical description of the residuals, this work allows uncertainty of the small strain shear modulus to be included in probabilistic studies.
\end{abstract}

Keywords: Shear Modulus, Small Strain, In-situ, Mixed Effects Regression

\section{Introduction}

The small strain shear modulus $\left(\mathrm{G}_{\max }\right)$ of soils is an essential element in many aspects of geotechnical earthquake engineering. At strains smaller than the linear cyclic threshold shear strain, $\gamma_{t 1}$, soils exhibit linear elastic behavior and the shear modulus is considered to be a constant maximum value, $G_{\max }$ [1]. The in-situ small strain shear modulus can be estimated from in-situ shear wave velocity $\left(\mathrm{V}_{\mathrm{s}}\right)$ measurements using $G_{\max }=\rho \times V_{s}^{2}$, where $\rho$ is the density of the soil. In-situ tests are costly and time consuming compared with simple laboratory index tests performed on borehole cuttings that measure soil characteristics such as plasticity index, coefficient of uniformity and water content, among others. In addition, depending on the method used, in-situ tests may measure an average $V_{s}$ value for large volumes of soil and miss variations in $V_{s}$ due to thin layers.

Given the importance of $\mathrm{G}_{\max }$ and the relative scarcity and cost of in-situ seismic measurements, many researchers have developed empirical relations to estimate $\mathrm{G}_{\max }$ based on results from dynamic laboratory tests (e.g. [2-4]). Results from laboratory tests generally give lower values of $\mathrm{G}_{\max }$ than in-situ tests due in part to sample disturbance, loss or lack of cementation and soil structure, and the effect of confinement time [5-6]. It is common practice to adjust the results from empirical models developed from laboratory results with a constant factor (e.g. [7]) or a time dependent factor (e.g. [8]) to account for the discrepancy between in-situ and laboratory values of $\mathrm{G}_{\max }$.

${ }^{1}$ Corresponding author, present address: Norwegian Geotechnical Institute, Oslo, Norway 
Most existing models focus on small databases of particular soil types (e.g., sands from a given location). As a result, these equations are often only accurate for the soils for which they were developed and for a narrow range of soil conditions. Although they may be extremely useful for a specific application, they may not be easily extended to a larger range of materials or conditions. Furthermore, few models available in the literature provide a measure of uncertainty of the prediction of $\mathrm{G}_{\max }$. This paper presents a unified model for estimating the in-situ small strain shear modulus of clays, silts, sands, and gravels that also provides a measure of the uncertainty in $\mathrm{G}_{\max }$ that allows the model to be included in probabilistic studies.

We developed the model in two phases. First, we developed a model to predict the laboratory small strain shear modulus $\left(G_{\text {max,lab }}\right)$ using a mixed effects regression for a relatively large database of different soil types. Second, we collected a separate database to estimate the in-

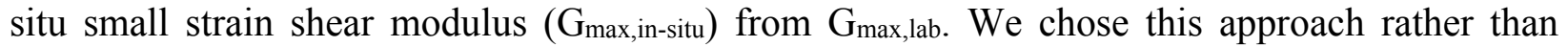
creating a model for $\mathrm{G}_{\text {max,in-situ }}$ directly because in laboratory tests soil parameters are known exactly and their effect on $\mathrm{G}_{\max }$ can be easily isolated and tested. In addition, the resulting model

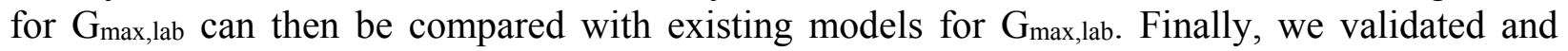
compared the model against a third database and versus four other models to estimate $\mathrm{G}_{\max }$.

\section{Database for $\mathbf{G}_{\mathrm{max}, \mathrm{lab}}$}

This work compiled laboratory measurements of $\mathrm{G}_{\text {max,lab }}$ from 1680 tests on 331 different soils from 28 studies. Table 1 lists the references of the collected database, as well as the test type (e.g., resonant column), sample type (i.e., undisturbed, reconstituted), and soil type (e.g., clay). Figure 1a shows the distribution of soil types in the $\mathrm{G}_{\max \text {,lab }}$ database according to their USCS classification and whether the soil was an 'undisturbed' sample or reconstituted in the laboratory, Figure $1 \mathrm{~b}$ shows the distribution of the number of tests according to general soil type, Figure 1c shows the mean effective confining pressure $\left(\sigma^{\prime} \mathrm{m}\right)$ versus void ratio (e) distribution for all of the tests, and Figure 1d plots the liquid limit (LL) versus the plasticity index (PI) for all of the cohesive soils in the database.

The PI and USCS designation was known for each of the 331 soils, however, the fines content (FC) was known for only 212 soils. When no fines content information was available for a given soil, we used the average value of the USCS designation as an estimate. Specifically, we used $\mathrm{FC}=2.5 \%$ for clean coarse grained soils ( $\mathrm{SW}, \mathrm{SP}, \mathrm{GW}$, and GP); FC $=8.5 \%$ for coarse grained soils with dual classification (e.g., SP-SM); FC $=31 \%$ for soils with USCS designations of SM, SC, GM, and GC; and $\mathrm{FC}=75 \%$ for fine-grained soils (i.e., $\mathrm{ML}, \mathrm{MH}, \mathrm{CL}$, and $\mathrm{CH}$ ).

The coefficient of uniformity $\left(\mathrm{C}_{\mathrm{u}}\right)$ was known only for soils with $\mathrm{FC}<50 \%$, and only 102 of the 331 soils reported the mean grain size (D50). There was not enough data regarding the number of loading cycles, excitation frequency, confinement time, or other parameters to estimate their effects on $G_{m a x}$,lab. However, Darendeli [6] and Lanzo et al. [9] reported that the number of

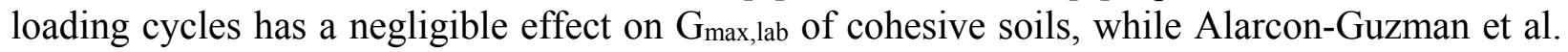
[10] and Lo Presti et al. [11-12] reported similar observations for cohesionless soils. Darendeli

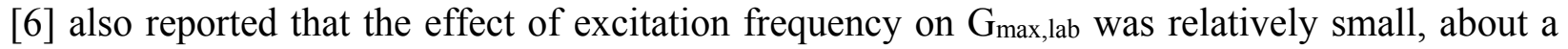

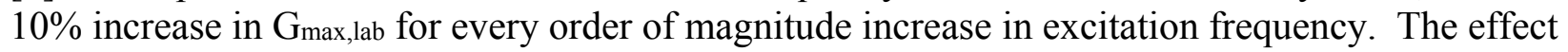
of confining time was assumed to be relatively small for the $G_{\text {max,lab }}$ database because a majority of the tests were either conducted at confining pressures greater than in-situ pressures or were from reconstituted samples using relatively short confining times. 


\section{Mixed Effects Regression Model for $\mathbf{G}_{\text {max,lab }}$}

Previous studies derived models for $\mathrm{G}_{\text {max,lab }}$ using least squares regression, which gives equal weight to each test. This method of analysis is appropriate when regression is done on a single soil or when there are an equal number of tests per soil. In the Gmax,lab database used in this study there are soils with more than 20 tests and soils with only three recorded tests. Therefore, it is not appropriate to analyze the data with a least squares regression because it would give a disproportionate weight to soils with significantly more data. Instead, this work selected a mixed effects procedure [13] to calculate the regression coefficients for the $\mathrm{G}_{\max , \text { lab }}$ model.

For mixed effects models, the error is divided into within group error $(\varepsilon)$ and between group error $(\eta)$ terms. The within group and between group error terms are assumed to be independent normally distributed with standard deviation $\phi$ and $\tau$ respectively. The total standard deviation for the model is computed as $\sigma=\sqrt{\phi^{2}+\tau^{2}}$.

This work found that $G_{\max , l a b}$ followed a log normal distribution. The natural log of the within and between soil residuals were found to be normally distributed per the $\chi^{2}$ test at a significance level of $95 \%$. All of the residuals and standard deviations are therefore in natural $\log$ units. This work applied the mixed effects model to the $\mathrm{G}_{\max , \text { lab }}$ database as:

$$
\ln \left[G_{\text {max }, l a b, i, j}\right]=\ln \left[f\left(\psi_{i}, \theta_{i, j}\right)\right]+\eta_{i}+\varepsilon_{i, j}
$$

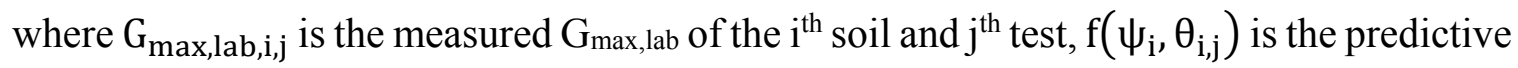

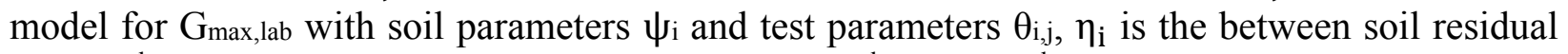
for the $\mathrm{i}^{\text {th }}$ soil and $\varepsilon_{\mathrm{i}, \mathrm{j}}$ is the within soil residual for the $\mathrm{i}^{\text {th }}$ soil and $\mathrm{j}^{\text {th }}$ test. Soil parameters $\psi_{\mathrm{i}}$ include PI, FC, D50, $\mathrm{C}_{\mathrm{u}}$, and sample type (reconstituted or 'undisturbed'). Test parameters $\theta_{\mathrm{i}, \mathrm{j}}$ include $\sigma$ ' $\mathrm{m}$, e, overconsolidation ratio (OCR), and test type. Test types include resonant column, torsional shear, cyclic triaxial, direct simple shear, bender element, and flat plate dilatometer.

\section{Development of the Model to Estimate $G_{\text {max,lab }}$}

The effect of void ratio on $G_{\text {max,lab }}$ was analyzed first by performing a mixed effects regression for tests with OCR $=1$ and $\sigma^{\prime}{ }_{m}=1$ atmosphere. This study determined coefficients for both the Hardin [2] void ratio model (equation (2)) and the model proposed by Jamiolkowski et al. [3] (equation (3)) shown below, where $\mathrm{a}_{1}, \mathrm{a}_{2}, \mathrm{a}_{3}$, and $\mathrm{c}_{1}$ and $\mathrm{c}_{2}$ are constants and $\mathrm{p}_{\text {at }}$ is atmospheric pressure.

$$
\begin{gathered}
\ln \left(G_{\text {max }, l a b, i, j} / p_{a t}\right)=\ln \left[a_{1} /\left(a_{2}+e_{i, j}^{a_{3}}\right)\right]+\eta_{i}+\varepsilon_{i, j} \\
\ln \left(G_{\text {max }, l a b, i, j} / p_{a t}\right)=\ln \left[c_{1} \times e_{i, j}^{c_{2}}\right]+\eta_{i}+\varepsilon_{i, j}
\end{gathered}
$$

The void ratio model proposed by Jamiolkowski et al. [3] gave a slightly smaller (0.414) within soil standard error than the Hardin [2] model (0.432). We conducted the remaining analyses with both models and found that the Jamiolkowski et al. [3] void ratio model also gave a smaller standard deviation for the final model than the void ratio formulation proposed by Hardin [2]. The rest of the paper uses the Jamiolkowski et al. [3] formulation for the void ratio and the coefficients listed were derived for this model. Table 2 lists the value of $\mathrm{c}_{2}$ and its standard error. The coefficient is similar to that proposed in the original formulation by Jamiolkowski et al. [3]. 
Menq [4] reported that the value of $c_{2}$ is dependent on $D_{50}$ for cohesionless soils. To study the influence of soil parameters such as D50 on $\mathrm{c}_{2}$, we separated the data into different bins according to the soil parameter and conducted mixed effects regression separately for each bin. We found that coefficient $\mathrm{c}_{2}$ had no clear trend with PI, FC, $\mathrm{D}_{50}$, or $\mathrm{C}_{\mathrm{u}}$ for the soils investigated in this study.

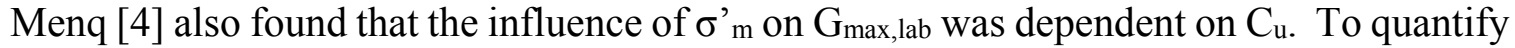
the effect of the mean effective stress $\sigma^{\prime}$ m on $G_{m a x}$,ab and examine the cross correlation with soil parameters $\mathrm{PI}, \mathrm{FC}, \mathrm{D}_{50}$, and $\mathrm{C}_{\mathrm{u}}$, we separated the data into different bins according to the soil parameter and conducted mixed effects regression separately for each bin, using equation (4) for all tests in the database with $\mathrm{OCR}=1$. The value of coefficient $\mathrm{c}_{2}$ was kept fixed at the value listed in Table 2.

$$
\ln \left(G_{\max , l a b, i, j} / p_{a t}\right)=\ln \left[c_{1} \times e_{i, j}^{c_{2}} \times\left(\sigma_{m, i, j}^{\prime} / p_{a t}\right)^{n}\right]+\eta_{i}+\varepsilon_{i, j}
$$

Figure 2 shows that the value of $\mathrm{n}$ has a clear increasing trend with $\mathrm{C}_{\mathrm{u}}$. When soils with $\mathrm{FC} \geq 30 \%$ are given a dummy value of $\mathrm{C}_{\mathrm{u}}=1$ they fit the trend described by the other soils. To model this trend, equation (5) was substituted for $\mathrm{n}$ in equation (4) and a mixed effects regression was conducted for all tests with $\mathrm{OCR}=1$, keeping $\mathrm{c}_{2}$ fixed at the value listed in Table 2, and giving soils with $\mathrm{FC} \geq 30 \%$ a dummy value of $\mathrm{C}_{\mathrm{u}}=1$ (i.e., in equation (5) $\mathrm{B}=1$ for $\mathrm{FC}<30 \%$ and $\mathrm{B}=$ 0 for $\mathrm{FC} \geq 30 \%$ ).

$$
n=c_{3} \times C_{u_{i}}^{B \times c_{4}}
$$

Table 2 lists the values of $\mathrm{c}_{3}$ and $\mathrm{c}_{4}$ and their standard errors. Figure 2 shows that equation (5) and the model derived for $\mathrm{n}$ by Menq [4] for cohesionless soils are similar.

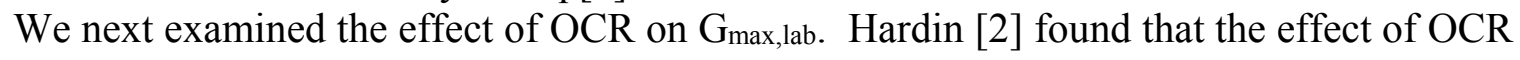

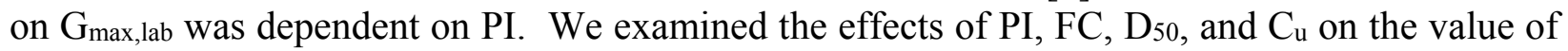
the OCR coefficient $\mathrm{k}$ in the same manner as for coefficient $\mathrm{c}_{2}$ and $\mathrm{n}$, using equation (6) and all tests in the database.

$$
\ln \left(G_{\max , l a b, i, j} / p_{a t}\right)=\ln \left[c_{1} \times e_{i, j}^{c_{2}} \times\left(\sigma_{m, i, j}^{\prime} / p_{a t}\right)^{n} \times O C R_{i, j}^{k}\right]+\eta_{i}+\varepsilon_{i, j}
$$

Figure 3 shows that the value of $\mathrm{k}$ has a clear increasing trend with PI up to about PI $=50$, which can be modeled by a power law as shown in equation (7). Similar to the model proposed by Hardin [2], this work capped the value of $k$ at 0.5 because the trend appears to level off and the data do not support a continuation of the curve.

$$
k=c_{5} \times\left(\frac{P I_{i}}{100}\right)^{c_{6}} \leq 0.5
$$

Figure 3 shows equation (7) compared to the model proposed by Hardin [2]. We found that as PI increases $\mathrm{k}$ increases but at an increasing rate, whereas Hardin [2] proposed a model with a decreasing rate. For PI less than $15 \%$, PI has a negligible or very modest effect on the value of $\mathrm{k}$. We substituted equation (7) into equation (6) and conducted a mixed effects regression for 
all tests in the database, keeping the values of $c_{2}, c_{3}$, and $c_{4}$ fixed at the values listed in Table 2 . Table 2 lists the values of $\mathrm{c}_{5}$ and $\mathrm{c}_{6}$ and their standard errors.

Figure 4 shows the between soil residuals $(\eta)$ for equation (6) plotted versus PI, FC, D50, and $\mathrm{Cu}_{\mathrm{u}}$. There is a slight decreasing trend with PI, FC, and $\mathrm{C}_{\mathrm{u}}$, which agrees with the results of the studies done by Kagawa [14] and Kallioglou et al. [15]; Yamada et al. [16]; and Iwasaki and Tatsuoka [17] and Menq [4], respectively. In contrast to reports by Seed et al. [18] and Ishihara [19], there appears to be no trend with $\mathrm{D}_{50}$.

We separated the between soil residuals into different bins according to FC to quantify the effects of the between soil parameters. When the between soil residuals were distributed by their FC value, there was no trend with PI for soils with $\mathrm{FC}<30 \%$, and no trend with $\mathrm{C}_{\mathrm{u}}$ for soils with $\mathrm{FC}>30 \%$. Other than this break at approximately $\mathrm{FC}=30 \%$, the trends for PI and $\mathrm{C}_{\mathrm{u}}$ do not show dependence on fines content. Based on this analysis, we developed equation (8) and equation (9) as shown below:

$$
\begin{gathered}
A=\left(F C_{i}+1\right)^{c_{7}} \times\left[C_{u_{i}}^{c_{8}} \times B+\left(P I_{i}+1\right)^{c_{9}} \times(1-B)\right] \\
B= \begin{cases}1 & \text { for } F C<30 \% \\
0 & \text { for } F C \geq 30 \%\end{cases}
\end{gathered}
$$

where the fines content, $\mathrm{FC}$ is in percent. To calculate the effect of FC, PI, and $\mathrm{C}_{\mathrm{u}}$ on $\mathrm{G}_{\max , \mathrm{lab}}$, we added equation (8) into equation (6) to give equation (10), then performed a mixed effects regression using equation (10) for all tests in the database. We kept the values of $\mathrm{c}_{2}$ through $\mathrm{c}_{6}$ fixed at the values listed in Table 2 .

$$
\begin{aligned}
\ln \left(G_{\max , l a b, i, j} /\right. & \left.p_{a t}\right) \\
& =\ln \left[c_{1} \times e_{i, j}^{c_{2}} \times\left(\sigma_{m, i, j}^{\prime} / p_{a t}\right)^{n} \times O C R_{i, j}^{k} \times\left(F C_{i}+1\right)^{c_{7}}\right. \\
& \left.\times\left[C_{u_{i}}^{c_{8}} \times B+\left(P I_{i}+1\right)^{c_{9}} \times(1-B)\right]\right]+\eta_{i}+\varepsilon_{i, j}
\end{aligned}
$$

The mixed effects regression calculated a value of the PI coefficient $\mathrm{c}_{9}=-0.012$, with a standard error of 0.021. Because the standard error of $\mathrm{c}_{9}$ was greater than the actual value of coefficient $\mathrm{c}_{9}$, it suggested that PI was not a good predictor of $\mathrm{G}_{\max }$, lab in the context of equation (10). As a result, equation (10) was modified to equation (11) by removing the PI term:

$$
\begin{aligned}
\ln \left(G_{\max , l a b, i, j} /\right. & \left.p_{a t}\right) \\
& =\ln \left[c_{1} \times e_{i, j}^{c_{2}} \times\left(\sigma_{m, i, j}^{\prime} / p_{a t}\right)^{n} \times O C R_{i, j}^{k} \times\left(F C_{i}+1\right)^{c_{7}}\right. \\
& \left.\times\left[1+B\left(C_{u_{i}}^{c_{8}}-1\right)\right]\right]+\eta_{i}+\varepsilon_{i, j}
\end{aligned}
$$

We then performed a mixed effects regression using equation (11) and all tests in the database. The values of $\mathrm{c}_{2}$ through $\mathrm{c}_{6}$ were kept fixed at the values listed in Table 2 . Figure 5 shows the between soil residuals ( $\eta$ ) for equation (11). It shows that there is no trend with PI, FC, $\mathrm{D}_{50}$ or $\mathrm{C}_{\mathrm{u}}$, which further supports the decision to drop the PI term from equation (10). Section 5 discusses the appropriateness of each parameter in detail. Table 2 lists the values and standard errors of $\mathrm{c}_{7}$ and $\mathrm{c}_{8}$. 
Finally, we performed a one way analysis of variance (ANOVA) test to determine whether to distinguish between reconstituted and 'undisturbed' samples, and another ANOVA test of the within soil residuals for each test type (e.g., resonant column, torsional shear). The ANOVA test of the between soil residuals for reconstituted and 'undisturbed' samples yielded a p-value of 0.7545 , or $75 \%$, and for test type a p-value of $1(100 \%)$. This means that equation (11) predicts $\mathrm{G}_{\text {max,lab }}$ equally well for reconstituted and undisturbed soil samples, as well as for different laboratory test types, and that the data do not support distinguishing between them when estimating

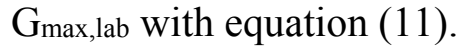

We allowed coefficient $\mathrm{c}_{1}$ to vary with each model. Table 3 lists the different values of $\mathrm{c}_{1}$ for each equation. It is important to remember that equation (3) was derived only for tests with $\sigma^{\prime}{ }_{m}=1$ atmosphere and OCR $=1$, equation (4) only for tests with OCR $=1$, and equations (6) and (11) for all tests in the database.

To study the influence of the parameters investigated in this study on the standard deviation we separated the data into different bins and conducted mixed effects regression separately for each bin. We found that the standard deviation of equation (11) was independent of all the parameters considered $\sigma$ 'm, PI, e, OCR, PI, D50, and $\mathrm{Cu}_{\mathrm{u}}$.

\section{Evaluation of the $\mathbf{G}_{\mathrm{max}, \mathrm{lab}}$ Model}

It is expected that as more parameters are added to a model the better the model will be able to fit the data. However, it is not desirable to create a model that fits only the collected data

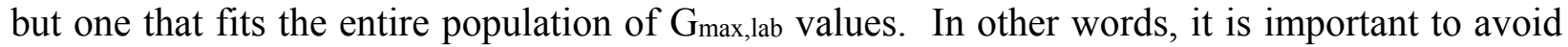
over parameterization. One way to measure whether the change in the quality of the fit is sufficient to justify the greater complexity of the model is through a log-likelihood ratio test.

The log-likelihood ratio test compares the log-likelihoods of two models, where one model is a special case of the other. This is achieved by constraining one or more of the parameters in the more complex model to be fixed values in the simpler model. A small p-value implies that the more complex model is appropriate, whereas a large p-value means it is not. To test the appropriateness of adding additional parameters to the $\mathrm{G}_{\text {max,lab }}$ model, we conducted log-likelihood ratio tests between equations (3) and (4), (4) and (6), (6) and (10), and (6) and (11). Table 4 shows the $p$-values of the log-likelihood ratio tests for each pair of equations. Table 4 also lists the within soil $(\phi)$, between soil $(\tau)$, and total standard deviation $(\sigma)$ computed for each equation from all of the data. The small p-values shown in Table 4 for equations (4) and (6) indicate that there is a significant dependence of $\mathrm{G}_{\text {max,lab }}$ on the proposed formulations for $\sigma$ ' $m$ and OCR. The decrease in the total standard deviation from equations (3) to (4) and from equations (4) to (6) confirms this finding. The p-value for equation (10), which adds the effect of PI, $\mathrm{FC}$, and $\mathrm{Cu}_{\mathrm{u}}$, is greater than 0.05 , which indicates that not all of the input variables are necessary, whereas the $\mathrm{p}$-value for equation (11), which only adds the effect of $\mathrm{FC}$ and $\mathrm{C}_{\mathrm{u}}$ to equation (6), is less than 0.05 . In addition, the standard deviations of equations (10) and (11) are the same. This further supports the decision to remove the PI term from the model.

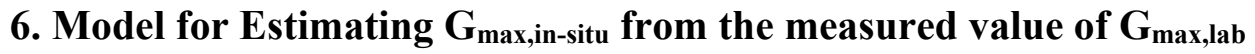

Equation (11) estimates the mean value of the small strain shear modulus based on laboratory data. However, values of $\mathrm{G}_{\max , \text { lab }}$ are different from values of $\mathrm{G}_{\text {max,in-situ }}$ due partially to sample disturbance, loss of cementation and structure, and the effect of confinement time $\left(\mathrm{tg}_{\mathrm{g}}\right)$. This section describes the development of a model to determine $G_{\text {max,in-situ }}$ from measured values of 
$\mathrm{G}_{\max , \text { lab. }}$ We collected data from 70 soils where $\mathrm{G}_{\max }$ was measured in-situ and in the laboratory at the same effective confining pressure $\left(\sigma^{\prime} \mathrm{m}\right)$. All of the soils in the in-situ database are from Holocene deposits or beneath newly placed embankments. Table 5 lists the references of the studies, as well as the tested soil and the in-situ and laboratory test type. Figure 6a shows the distribution of soil types in the Gmax,in-situ database according to their USCS classification, Figure $6 \mathrm{~b}$ shows the distribution of the number of tests according to general soil type, Figure 6c shows $\sigma_{m}^{\prime}$ versus e for all of the tests, and Figure $6 \mathrm{~d}$ plots LL versus PI for all of the cohesive soils in the $\mathrm{G}_{\mathrm{max} \text {,in-situ database. }}$

We examined the correlation between the measured values of $\mathrm{G}_{\max , \text { lab }}$ and $\mathrm{G}_{\mathrm{max} \text {,in-situ }}$ by performing least squares regression on the data using linear, logarithmic, power, polynomial, and exponential equation forms. The power formulation, shown in equation (12) and Figure 7a, gave the best fit to the data $\left(\mathrm{R}^{2}=0.91\right)$ :

$$
\ln \left(G_{\max , \text { in-situ }}\right)=\ln \left(0.78 \times G_{\max , l a b}^{1.10}\right)+\omega
$$

where $\omega$ is the in-situ residual with standard deviation $\kappa=0.36$. We found $\kappa$ to be independent of soil and test parameters. Figure $7 \mathrm{~b}$ shows that there is no bias in equation (12) for the collected data. Figure $7 \mathrm{c}$ and Figure $7 \mathrm{~d}$ show the in-situ residuals ( $\omega$ ) from equation (12) versus PI and $\sigma^{\prime} \mathrm{m}$. These plots revealed no significant trends of the in-situ residuals with either parameter. These results are similar to those presented by Chiara and Stokoe [7]. They found that the relation between $G_{\text {max,in-situ }}$ and $G_{\text {max,lab }}$ is best described by a power law, and that $\sigma$ 'm, PI, and depth have a negligible effect. They also found that $G_{\text {max,lab }}$ tends to be larger than $G_{\text {max,in-situ at }}$

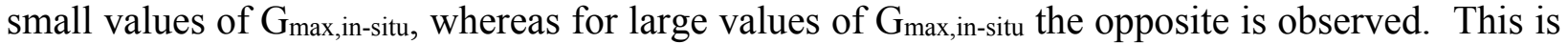
because soils with small values of $\mathrm{G}_{\max \text {,in-situ }}$ are generally loose and uncemented, and they become denser due to sampling. Stiffer soils, on the other hand, tend to have larger in-situ than laboratory $\mathrm{G}_{\max }$ values because sampling can break bonds created by cementation and can cause a rearrangement of soil particles that destroys the 'structure' of the sample.

We conducted a one way ANOVA test of the in-situ residuals on the in-situ field test type (downhole, crosshole, SASW, and suspension logger). The ANOVA test gave a p-value of 0.81 (81\%), which implies that the data do not support distinguishing between in-situ test type when predicting $G_{m a x}$,in-situ $u$ using equation (12). A discussion of the different field and laboratory tests is outside the scope of this paper and can be found in the literature (e.g., [2, 8]). Different in-situ and laboratory test types have different uncertainties in the measured value of $G_{\max }$ and these are not considered in the proposed model. The standard deviation reported here represents only the uncertainty in the fit of the model, not in the accuracy of either the in-situ or laboratory tests.

To create one model to estimate the in-situ small strain shear modulus from soil and test parameters, we combined equations (11) and (12) into equation (13). The total standard deviation ( $\left.\sigma_{\text {Total }}\right)$ was determined for equation (13) with equation (14). Table 4 lists the within $(\phi)$ and between $(\tau)$ soil standard deviations.

$$
\begin{gathered}
\ln \left(G_{\text {max }, \text { in }- \text { situ }, i, j} / p_{a t}\right)= \\
\ln \left[0.78 \times\left(c_{1} \times e_{i, j}^{c_{2}} \times\left(\sigma_{m, i, j}^{\prime} / p_{a t}\right)^{n} \times O C R_{i, j}^{k} \times\left(F C_{i}+1\right)^{c_{7}}\right.\right. \\
\left.\left.\times\left[1+B\left(C_{u_{i}}^{c_{8}}-1\right)\right]\right)^{1.10}\right]+\eta_{i}+\varepsilon_{i, j}+\omega \\
\sigma_{\text {Total }}=\sqrt{\phi^{2}+\tau^{2}+\kappa^{2}}
\end{gathered}
$$


The value of $\sigma_{\text {Total }}$ for equation (13) is 0.58 natural log units, which is comparable to the total standard deviation found for equations to predict pseudo-acceleration response spectra (approximately 0.5 to 0.8 natural $\log$ units).

\section{Model Validation and Comparison}

We validated and compared equation (13) against existing models using a third database. The validation database consists of 344 samples of 259 different soils from 7 studies. Table 6 lists the references of the studies, as well as the in-situ test and soil type. Figure 8 plots information for the validation database in a similar form as for the $G_{\max , \text { lab }}$ and $G_{\text {max,in-situ }}$ databases shown in Figure 1 and Figure 6, respectively.

We compared equation (13) with the models proposed by Jamiolkowski et al. [3] and Hardin [2] for the entire validation database, and for subsets of the validation database where FC $<30 \%$ and another subset where FC $\geq 30 \%$. In addition, equation (13) was compared with the models proposed by Kokusho et al. [20] and Kallioglou et al. [15] for the subset of soils with FC

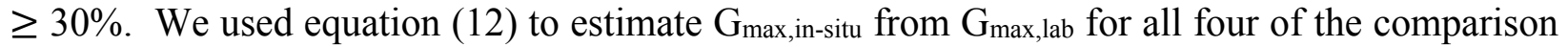
models to be consistent with equation (13). Equation (12) was developed independently from the equation to predict $\mathrm{G}_{\max , \text { lab }}$ and therefore is not biased in favor of that model.

Table 7 lists the mean, median, and standard deviation of the total residuals for each model for results of the entire database, results for soils in the validation database with $\mathrm{FC}<30 \%$, and results for soils in the validation database with $\mathrm{FC} \geq 30 \%$. When the mean and median are close

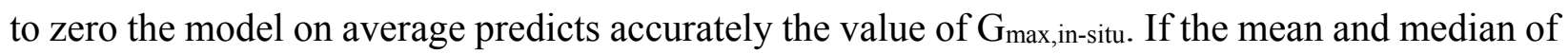
the residuals are positive, the model tends to under-predict, and if they are negative the model tends to over-predict the measured values. The mean and median values of the total residuals for equation (13) are the closest to zero of all the considered models and datasets. The Jamiolkowski et al. [3] model has similar mean and median values as equation (13) for soils with $\mathrm{FC}<30 \%$, but for all soils and for soils with $\mathrm{FC} \geq 30 \%$ Jamiolkowski et al. [3] tend to over-predict the value of $\mathrm{G}_{\text {max,in-situ. }}$ The Hardin [2] model has similar mean and median values as equation (13) for soils with $\mathrm{FC} \geq 30 \%$ and for all soils, but under-predicts $\mathrm{G}_{\text {max,in-situ }}$ for soils with $\mathrm{FC}<30 \%$. The Kokusho et al. [20] and Kallioglou et al. [15] models tend to under-predict the value of $G_{\text {max,in-situ }}$ for soils with $\mathrm{FC} \geq 30 \%$. Equation (13) also has the smallest standard deviation of all the considered models for each dataset. The Jamiolkowski et al. [3] and Hardin [2] models have marginally larger standard deviations than equation (13) for each subset of the validation data, and the Kokusho et al. [20] and Kallioglou et al. [15] models have significantly larger standard deviations for soils with $\mathrm{FC} \geq 30 \%$.

\section{Summary and Conclusion}

This paper describes the development of a model to estimate $\mathrm{G}_{\max \text {,in-situ }}$ for Holocene soils from soil type and index test parameters routinely determined in site investigations. First, we

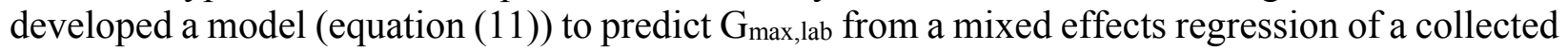
database that contains 1680 tests on 331 different soils. Second, we collected a separate database

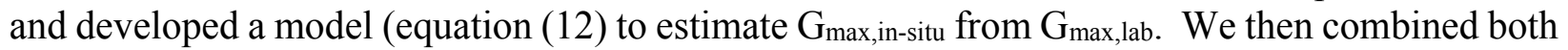

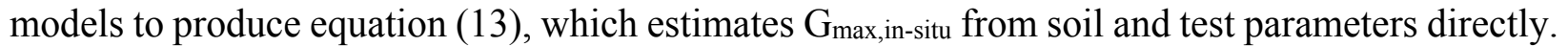
The final model is reproduced below. Table 2 lists coefficients $\mathrm{c}_{2}$ through $\mathrm{c}_{8}$, and Table 3 lists the value of $\mathrm{c}_{1}$. 


$$
\begin{gathered}
G_{\text {max,in-situ }} / p_{a t}= \\
0.78 \times\left[c_{1} \times e^{c_{2}} \times\left(\sigma_{m}^{\prime} / p_{a t}\right)^{n} \times O C R^{k} \times(F C+1)^{c_{7}}\right. \\
\left.\times\left[1+B\left(C_{u}{ }^{c_{8}}-1\right)\right]\right]^{1.10} \\
n=c_{3} \times C_{u}{ }^{B \times c_{4}} \\
k=c_{5} \times\left(\frac{P I}{100}\right)^{c_{6}} \leq 0.5 \\
B= \begin{cases}1 & \text { for } F C<30 \% \\
0 & \text { for } F C \geq 30 \%\end{cases}
\end{gathered}
$$

The total standard deviation is $\sigma_{\text {Total }}=0.58$. The estimate of the standard deviation allows the uncertainty of the small strain shear modulus to be included in probabilistic studies. The model is also unique from other models in that it includes a fines content dependent term for $\mathrm{C}_{\mathrm{u}}$ and a separate term for fines content, which allows a smooth transition from clean gravels and sands to silts and clays.

Finally, we collected a third database to validate and compare the model to other existing models. We compared the model with models by Jamiolkowski et al. [3], Hardin [2], Kokusho et al. [20], and Kallioglou et al. [15]. The residuals of the model developed in this paper had a mean and median closer to zero and a smaller standard deviation than the other four models considered. This demonstrates that the model is robust and can be used to estimate the in-situ small strain shear modulus of clays, silts, sands, and gravels.

\section{Acknowledgements}

This material is based upon work supported by the National Science Foundation under Grant No. CMMI 0928974 and by a National Science Foundation Graduate Research Fellowship for the first author. Any opinions, findings, and conclusions or recommendations expressed in this material are those of the author(s) and do not necessarily reflect the views of the National Science Foundation. The authors would also like to thank Professors Andrus, Kallioglou, Pagliaroli, Okur, and Yamada for their willingness to share their data.

\section{References}

[1] Vucetic, M. (1994). "Cyclic Threshold Shear Strains in Soils," Journal of Geotechnical Engineering, 120(12), 2208-2228.

[2] Hardin, B. (1978). "The nature of stress-strain behavior of soils," Proc. of Geotechnical Division Specialty Conference on Earthquake Engineering \& Soil Dynamics, ASCE, Pasadena, CA, Vol.1, 3-90.

[3] Jamiolkowski, M., Leroueil, S., and D.C.F. Lo Presti. (1991). "Design Parameters from Theory to Practice," Theme Lecture, Proc. Geo-Coast 91, Yokohama, Vol. 2, 877-917.

[4] Menq, F-Y. (2003). "Dynamic Properties of Sandy and Gravelly Soils," PhD dissertation, Univ. of Texas at Austin, Austin, Texas.

[5] Lefebvre, G., Leboeuf, D., Rahhal, M.E., Lacroix, A., Warde, J. and Stokoe, K.H. (1994). "Laboratory and field determinations of small-strain shear modulus for a structured Champlain clay," Canadian Geotechnical Journal $31(1), 61-70$.

[6] Darendeli, M. B. (2001). "Development of a new family of normalized modulus reduction and material damping curves," PhD dissertation, Univ. of Texas at Austin, Austin, Texas. 
[7] Chiara, N. and Stokoe, K.H. (2006). "Sample disturbance in resonant column test measurement of small strain shear wave velocity," Proc. Soil Stress-Strain Behavior: Measurement, Modeling and Analysis, 605-613.

[8] Anderson, D.G. and Stokoe, K.H. (1978). "Shear Modulus: A Time-Dependent Soil Property," Dynamic Geotechnical Testing. ASTM STP 654, ASTM, 66 - 90.

[9] Lanzo, G., Pagliaroli, A., Tommasi, P., and Chiocci F.L. (2009). "Simple shear testing of sensitive, very soft offshore clay for wide strain range," Canadian Geotechnical Journal 46 (11), 1277 - 1288.

[10] Alarcon-Guzman, A., Chameau, J. L., Leonards, G. A., and Frost, J. D. (1989). "Shear modulus and cyclic undrained behavior of sands," Soils and Foundations, 29(4), 105-119.

[11] LoPresti, D. C. F., Pallara, O., Lancellotta, R., and Maniscalco, R. (1993). "Monotonic and cyclic loading behavior of two sands at small strains," Geotechnical Testing Journal, 16(4), 409-424.

[12] Lo Presti, D.C.F., Jamiolkowski, M., Pallara, O., Cavallaro, A. \& Pedroni, S. (1997). "Shear modulus and damping of soils," Geotechnique, 47(3), 603-617.

[13] Pinheiro, J.C., and Bates, D.M., (2000). Mixed Effects Models in S and S-PLUS. Springer-Verlag, New York.

[14] Kagawa, T. (1992). "Moduli and damping factors of soft marine clays," Journal of Geotechnical Engineering, 118(9), 1360-1375.

[15] Kallioglou, P., Tika, Th. and Pitilakis, K. (2008). "Shear Modulus and Damping Ratio of Cohesive Soils," Journal of Earthquake Engineering, 12(6), 879 - 913.

[16] Yamada, S., Hyodo, M., Orense, R., and Dinesh, S. V. (2008). "Initial shear modulus of remolded sand-clay mixtures," Journal of Geotechnical and Geoenvironmental Engineering, 134(7), 960-971.

[17] Iwasaki, T., and Tatsuoka, F. (1977). "Effects of grain size and grading on dynamic shear moduli of sands," Soils and Foundations, 17 (3), 19-35.

[18] Seed, H. B., Wong, R. T., Idriss, I. M., and Tokimatsu, K. (1984). "Moduli and damping factors for dynamic analyses of cohesionless soils," Report, UBC/EERC 84-14, University of California, Berkeley, CA.

[19] Ishihara, K. (1996). "Soil Behavior in Earthquake Geotechnics," Oxford Science Publications 350p.

[20] Kokusho, T., Yoshida, Y. and Esashi, Y. (1982). "Dynamic properties of soft clay for a wide strain range," Soils and Foundations, 22 (4), 1-18.

[21] Athanasopoulos, G.A. (1993). "Effects of ageing and overconsolidation on the elastic stiffness of a remoulded clay," Geotechnical and Geological Engineering, 11(1), 51-65.

[22] Bellotti, R., Benoit, J., Fretti, C., and Jamiolkowski, M. (1997). "Stiffness of Toyoura sand from dilatometer tests," Journal of Geotechnical and Geoenvironmental Engineering, 123(9), 836-846.

[23] Borden, R. H., Shao, L., and Gupta, A. (1996). "Dynamic properties of Piedmont residual soils," Journal of Geotechnical Engineering, 122(10) 813-821.

[24] Cavallaro, A., Lo Presti, D.C.F., and Maugeri, M. (2000). "Dynamic geotechnical characterization of soils subjected to Umbria and Marches earthquakes," Earthquake Engineering 12th World Conference, Auckland, New Zealand.

[25] Chung, R. M., Yokel, F. Y., and Drnevich, V. P. (1984). "Evaluation of dynamic properties of sands by resonant column testing," Geotechnical Testing Journal, 7(2), 60-69.

[26] Doroudian, M. and Vucetic, M., (1995). "A Direct Simple Shear Device for Measuring Small-Strain Behavior," Geotechnical Testing Journal, 18(1), 69-85.

[27] EPRI (1993). "Guidelines for Determining Design Basis Ground Motions," Electric Power and Research Institute, Project, Report Vols. I-IV.

[28] Jovicic, V., and Coop, M. R. (1997). "Stiffness of coarse grained soils at small strains," Geotechnique, 47(3), 545-561.

[29] Kokusho, T. (1980). "Cyclic triaxial test of dynamic soil properties for wide strain range," Soils and Foundations, 20(2), 45-60.

[30] Lanzo, G., and Pagliaroli, A. (2006). "Stiffness of natural and reconstituted Augusta clay at small to medium strains," Proc. Soil Stress-Strain Behavior: Measurement, Modelling and Analysis, 323-331.

[31] Nigbor, R. (2012) "Resolution of Site Response Issues in the Northridge Earthquake (ROSRINE)," Personal communication, October 24, 2012.

[32] Okur, D.V., Ansal, A. (2007). "Stiffness degradation of natural fine grained soils during cyclic loading," Soil Dynamics and Earthquake Engineering, 27 (9), 843 - 854.

[33] S\&ME Inc. (1998). "Second report of seismic analysis - Daniel Island terminal, Charleston, South Carolina," Project Rep. No. 1131-97-741, Mount Pleasant, S.C.

[34] S\&ME Inc. (1993). "Seismic soil pile interaction analyses-Mark Clark expressway/Stono River crossings, Charleston, South Carolina," Project Rep. No. 1131-92-162, Mount Pleasant, S.C. 
[35] Saxena, S., and Reddy, K. (1989). "Dynamic moduli and damping ratios for Monterey No. 0 sand by resonant column tests," Soils and Foundations, 29(2), 37-51.

[36] Schneider, J.A., Hoyos, L., Jr., Mayne, P.W., Macari, E.J., and Rix, G.J. (1999). "Field and laboratory measurements of dynamic shear modulus of Piedmont residual soils," Behavioral Characteristics of Residual Soils, GSP 92, 12-25.

[37] Shibuya, S., Toshiyuki, T., Fukuda, F., and Degoshi, T. (1995). "Strain rate effects on shear modulus and damping of normally consolidated clays," Geotechnical Testing Journal, ASTM, 18(3), 365-375.

[38] Tika, Th., Kallioglou, P., Koninis, G., Michaelidis, P., Efthimiou, M., Pitilakis, K. (2010). "Dynamic properties of cemented soils from Cyprus," Bulletin of Engineering Geology and the Environment, 69 (2), 295-307.

[39] Yasuda, N., and Matsumoto, N. (1993). "Dynamic deformation characteristics of sands and rockfill materials," Canadian Geotechnical Journal, 30(5), 747-757.

[40] Yasuda, N., Ohta, N., and Nakamura, A. (1996). "Dynamic deformation characteristics of undisturbed riverbed gravels," Canadian Geotechnical Journal, 33(2), 237-247.

[41] Nikolaou, S. (2012). "Deep soft soil sites in the greater NYC metropolitan area," Personal communication, April 26, 2012.

[42] Pass, D.G. (1994). "Soil Characterization of the Deep Accelerometer Site at Treasure Island, San Francisco, California," M.Sc. Thesis, University of New Hampshire, Durham, New Hampshire.

[43] Shibuya, S. and Tanaka, H. (1996). "Estimate of elastic shear modulus in Holocene soil deposits," Soils and Foundations, 36(4), 45-55. 
Table 1. Data compiled to develop Gmax,lab model

\begin{tabular}{|c|c|c|c|}
\hline Reference & Test Type ${ }^{a}$ & Sample Type ${ }^{b}$ & Soil(s) Tested \\
\hline Alarcon-Guzman et al. 1989 & $\mathrm{RC}$ & $\mathrm{R}$ & Ottawa $20-30,50-70$ Sand \\
\hline Athanasopoulos 1993 & $\mathrm{RC}$ & $\mathrm{R}$ & Kaolinite \\
\hline Bellotti et al. 1997 & DMT & $\mathrm{R}$ & Toyoura Sand \\
\hline Borden et al. 1996 & $\mathrm{TS}, \mathrm{RC}$ & $\mathrm{U}$ & Soils from North Carolina \\
\hline Cavallaro et al. 2000 & $\mathrm{RC}$ & $\mathrm{U}$ & Fabriano Clay \\
\hline Chung et al. 1984 & $\mathrm{RC}$ & $\mathrm{R}$ & Monterey Sand \\
\hline Doroudian and Vucetic 1995 & DSS & $\mathrm{R}$ & Kaolinite \\
\hline EPRI 1994 & $\mathrm{RC}$ & $\mathrm{U}, \mathrm{R}$ & Soils from California and Taiwan \\
\hline Iwasaki and Tatsuoka 1977 & $\mathrm{RC}$ & $\mathrm{R}$ & Toyoura and Iruma Sand \\
\hline Jovicic and Coop 1997 & $\mathrm{BE}$ & $\mathrm{R}$ & Ham River and Dog's Bay Sand \\
\hline Kallioglou et al. 2008 & $\mathrm{RC}$ & $\mathrm{U}, \mathrm{R}$ & Soils from Greece and Cyprus \\
\hline Kokusho et al. 1982 & $\mathrm{CT}$ & $\mathrm{U}$ & Soils from Chiba, Japan \\
\hline Kokusho 1980 & $\mathrm{CT}$ & $\mathrm{R}$ & Toyoura Sand \\
\hline Lanzo and Pagliaroli 2006 & DSS & $\mathrm{U}, \mathrm{R}$ & Augusta Clay \\
\hline Lanzo et al. 2009 & DSS & $\mathrm{U}$ & Vasto Clay \\
\hline Lo Presti et al. 1997 & $\mathrm{RC}$ & $\mathrm{R}$ & Toyoura and Quiou Sand \\
\hline Lo Presti et al. 1993 & $\mathrm{RC}$ & $\mathrm{R}$ & Ticino and Quiou Sand \\
\hline Okur and Ansal 2007 & $\mathrm{CT}$ & $\mathrm{U}$ & Soils from Turkey \\
\hline Nigbor 2012 (ROSRINE) & $\mathrm{RC}, \mathrm{DSS}$ & $\mathrm{U}, \mathrm{R}$ & Soils from California \\
\hline S\&ME Inc 1993, 1998 & $\mathrm{TS}, \mathrm{RC}$ & $\mathrm{U}$ & Soils from Charleston, $\mathrm{SC}$ \\
\hline Saxena and Reddy 1989 & $\mathrm{RC}$ & $\mathrm{R}$ & Monterey Sand \\
\hline Schneider et al. 1999 & $\mathrm{RC}$ & $\mathrm{U}$ & Piedmont Residual Soils \\
\hline Seed et al. 1984 & $\mathrm{CT}$ & $\mathrm{R}$ & Oroville, Pyramid, Venado, Livermore Gravels \\
\hline Shibuya et al. 1995 & $\mathrm{TS}$ & $\mathrm{R}$ & Kiyohoro Clay and Kaolinite \\
\hline Tika et al. 2010 & $\mathrm{RC}$ & $\mathrm{U}$ & Soils from Cyprus \\
\hline Yamada et al. 2008 & TS & $\mathrm{U}, \mathrm{R}$ & Japanese Clays \\
\hline Yasuda and Matsumoto 1993 & TS & $\mathrm{R}$ & Toyoura Sand, Rockfill \\
\hline Yasuda et al. 1996 & CT & $\mathrm{R}$ & Riverbed Gravel \\
\hline
\end{tabular}

${ }^{\mathrm{a}} \mathrm{RC}=$ resonant column; $\mathrm{TS}=$ torsional shear; $\mathrm{CT}=$ cyclic triaxial; $\mathrm{DSS}=$ direct simple shear; $\mathrm{BE}=$ bender element; $\mathrm{DMT}=$ flat plate dilatometer

${ }^{\mathrm{b}} \mathrm{R}=$ reconstituted; $\mathrm{U}=$ 'undisturbed' 
a)

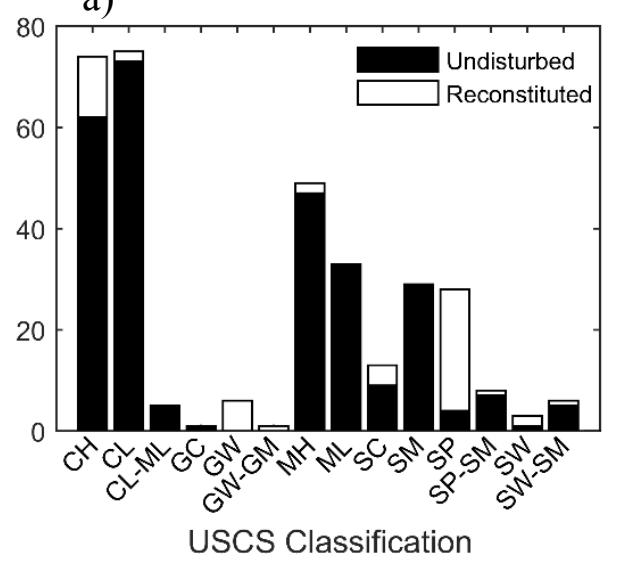

c)

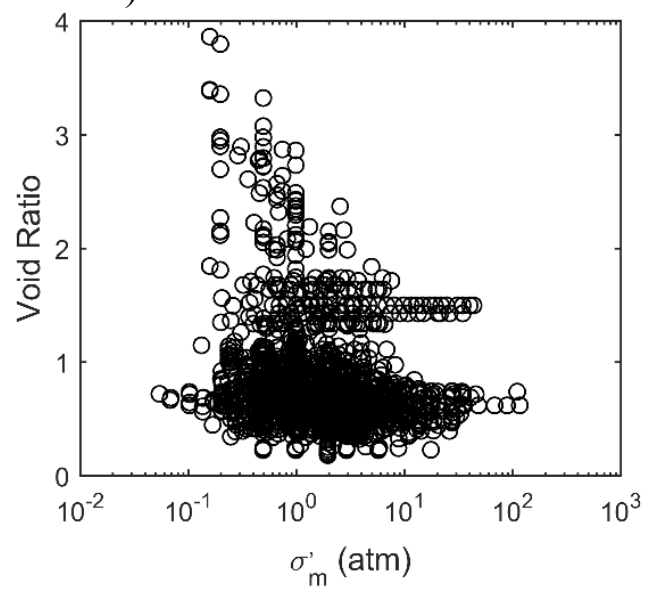

b)

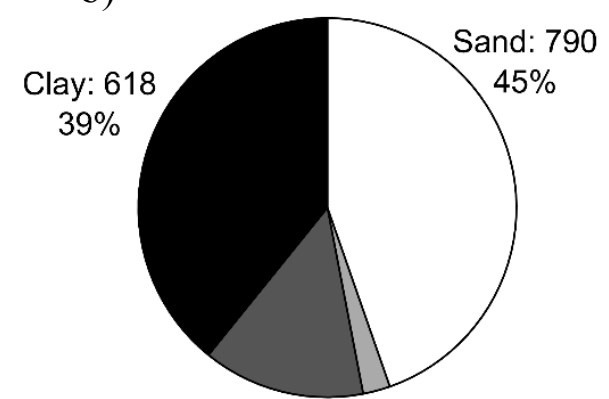

Silt: $233,14 \%$

Gravel: $39,2 \%$

d)

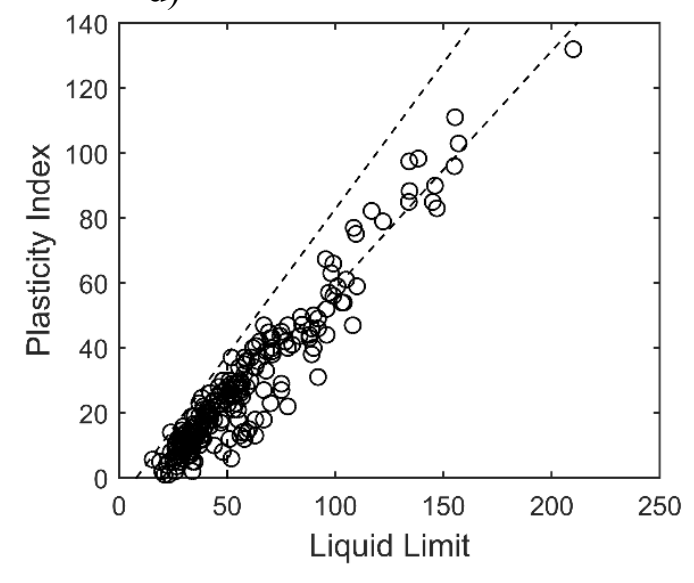

Figure 1. Characteristics of soils in the $G_{\text {max,lab }}$ database: a) USCS designation for each soil, b) number and percentage of tests for each general soil type, c) distribution of void ratio and $\sigma^{\prime}{ }_{m}$ for all tests, and d) plasticity characteristics of cohesive soils

Table 2. Coefficients and standard error for the proposed model of $\mathbf{G}_{\text {max,lab }}$

\begin{tabular}{ccc}
\hline Coefficient & Value & Standard Error \\
\hline $\mathrm{c}_{2}$ & -1.309 & 0.0817 \\
$\mathrm{c}_{3}$ & 0.465 & 0.0138 \\
$\mathrm{c}_{4}$ & 0.106 & 0.0102 \\
$\mathrm{c}_{5}$ & 2.022 & 0.0463 \\
$\mathrm{c}_{6}$ & 1.933 & 0.0231 \\
$\mathrm{c}_{7}$ & -0.124 & 0.0161 \\
$\mathrm{c}_{8}$ & -0.170 & 0.0308 \\
\hline
\end{tabular}


a)

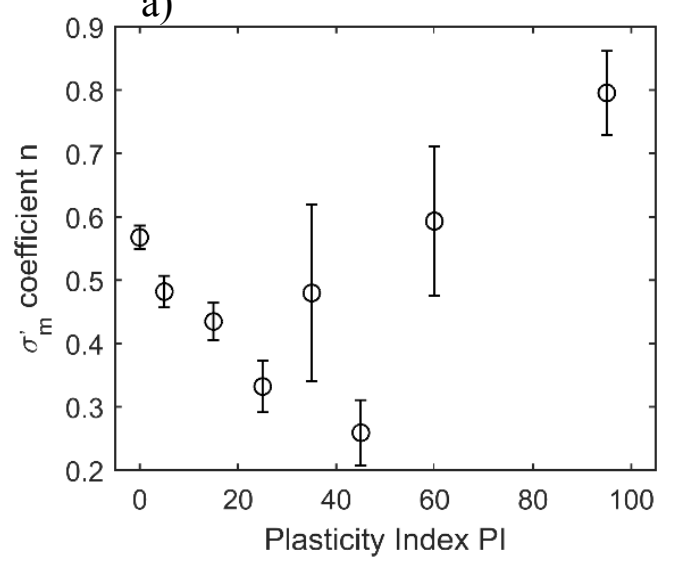

c)

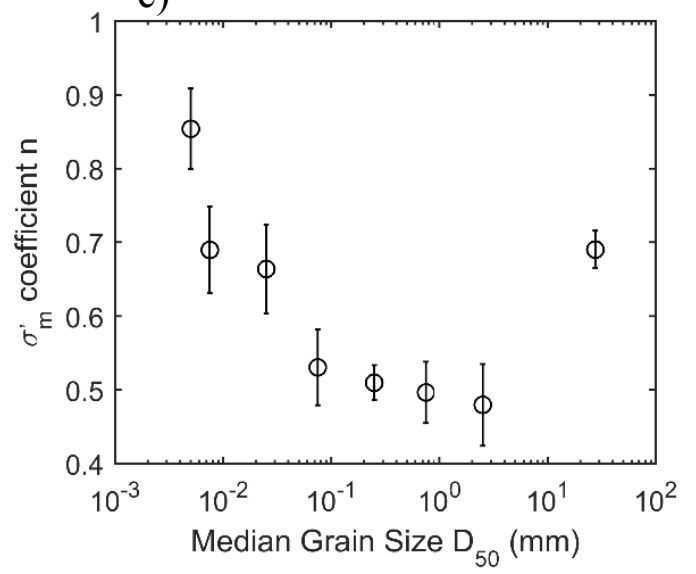

b)

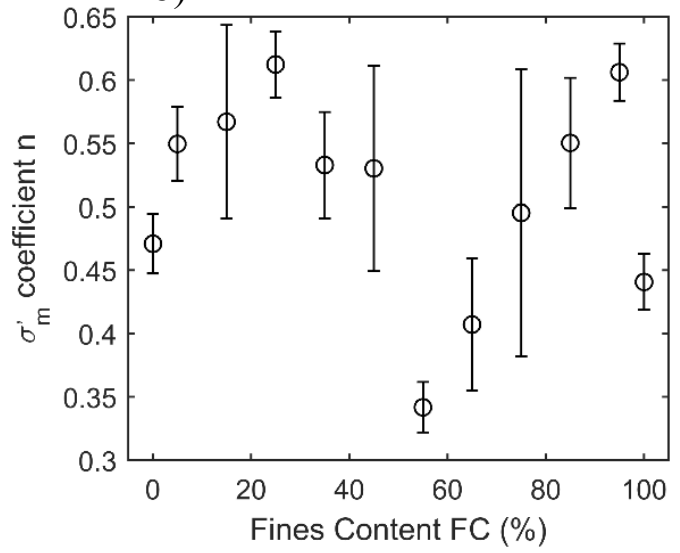

d)

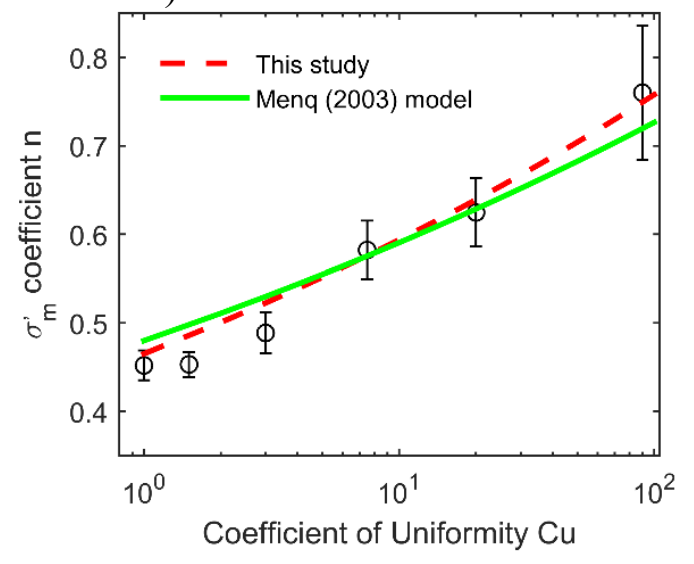

Figure 2. Dependence of coefficient n on a) PI, b) FC, c) $D_{50}$, and d) $C_{u}$, for tests with $O C R=1$, where the $C_{u}$ $=1$ bin is soils with $F C>\mathbf{3 0} \%$. Error bars are the standard errors of the predicted value of $n$. 
a)

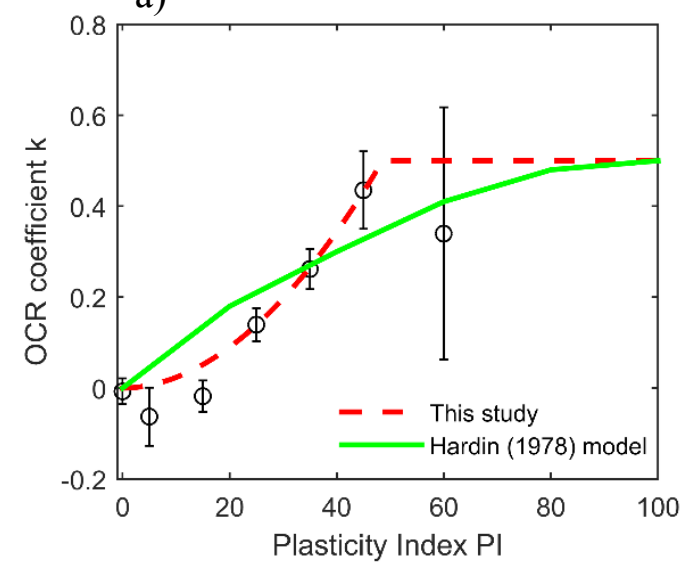

c)

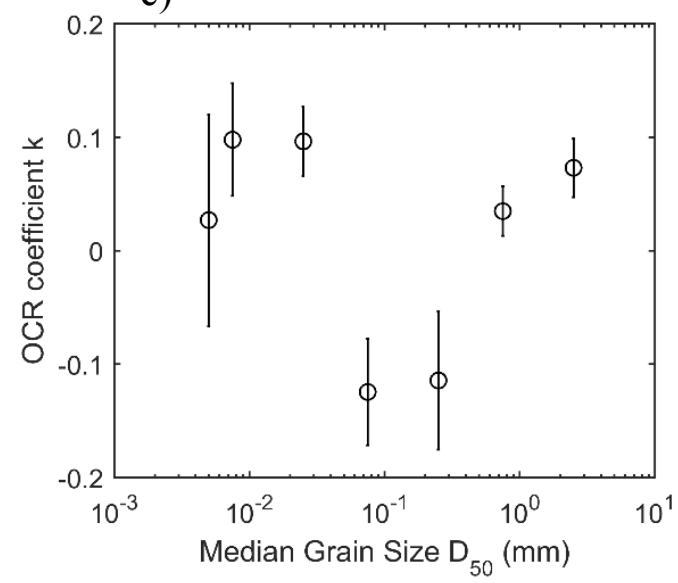

b)

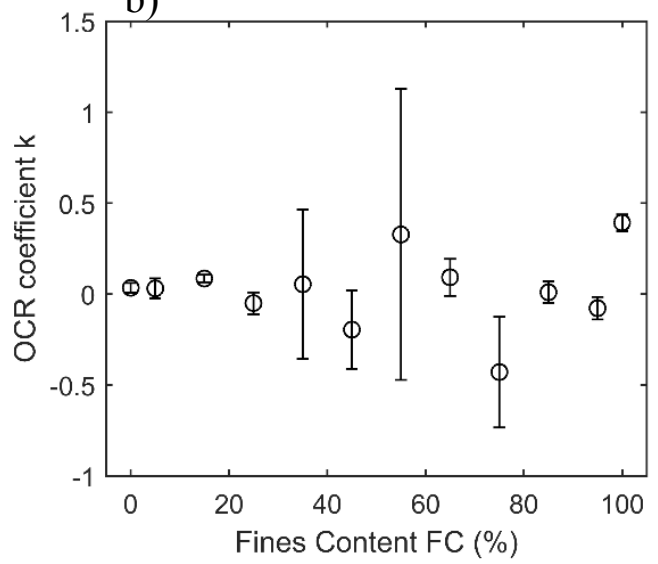

d)

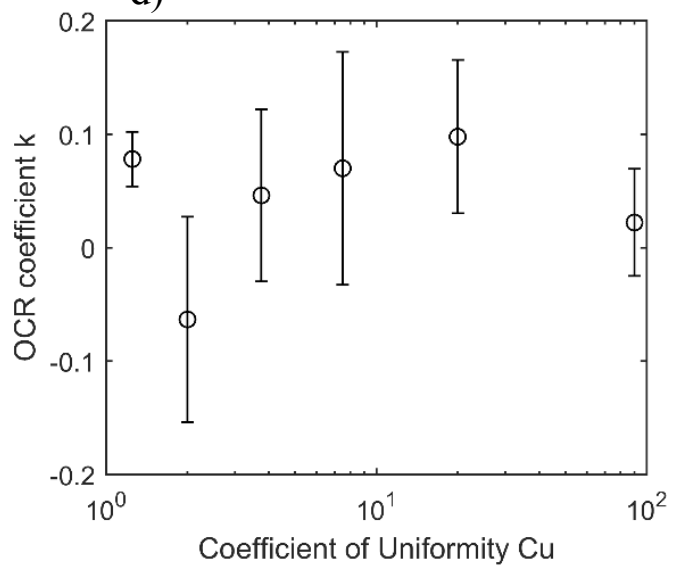

Figure 3. Dependence of coefficient $k$ on a) PI, b) FC, c) $D_{50}$, and d) $C_{u}$ for all tests. Error bars are the standard errors of the predicted value of $k$. The bin at $P I=60$ is for all soils with $P I>50$. 
a)

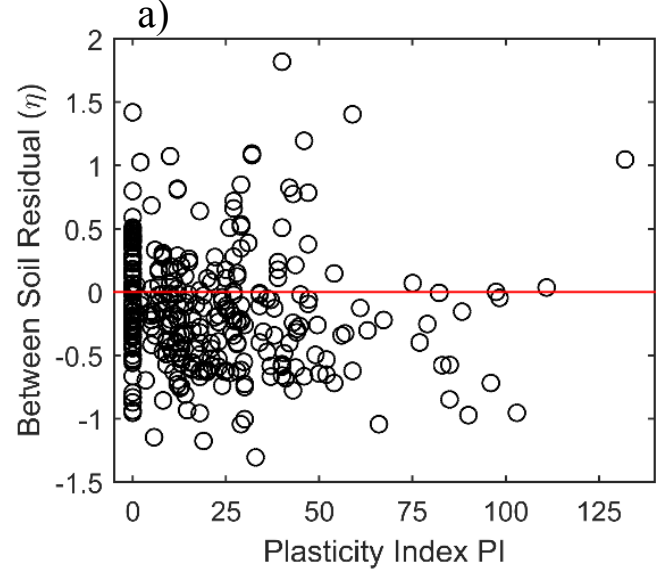

c)

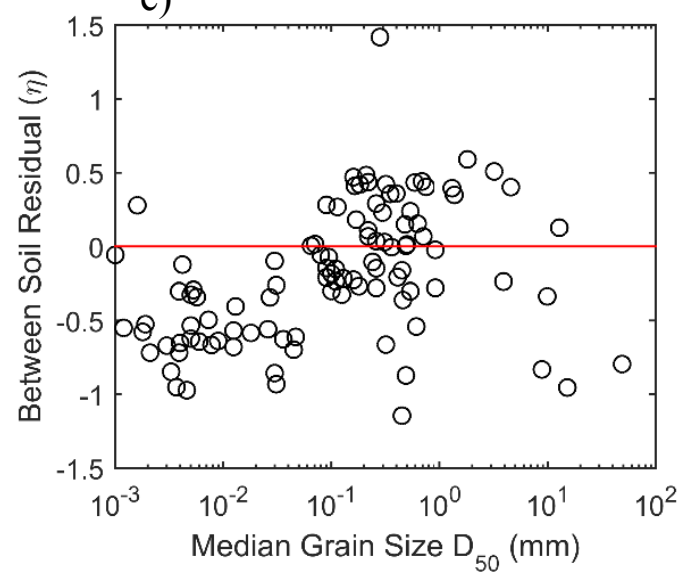

b)

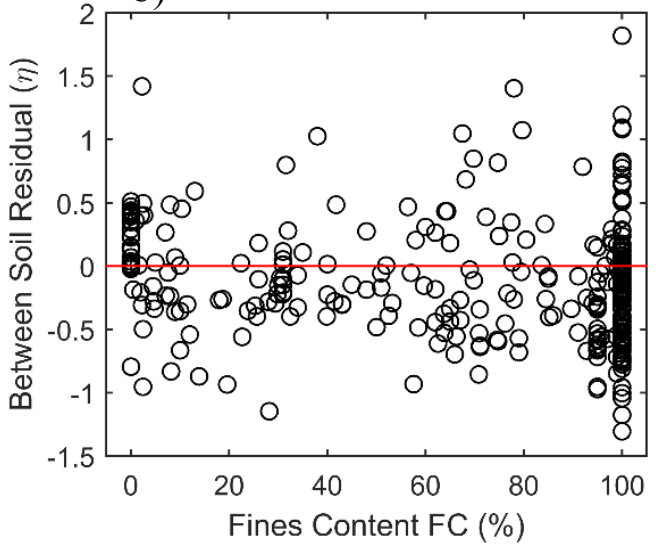

d)

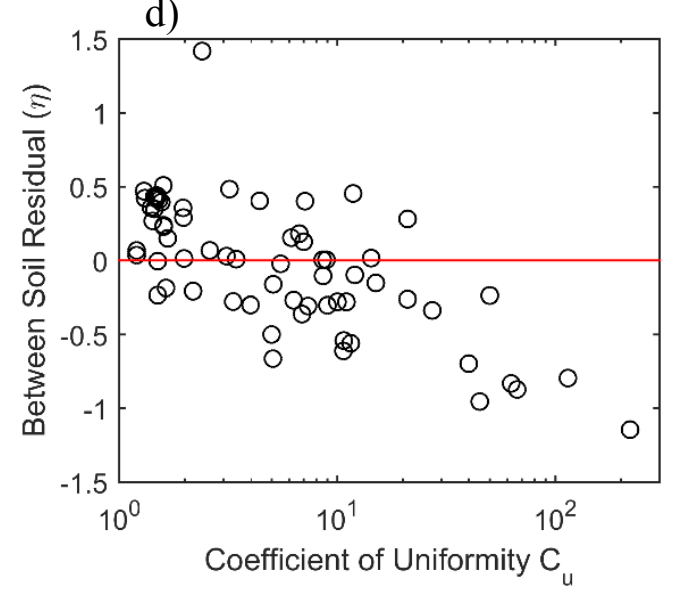

Figure 4. Between soil residuals $\eta$ for equation (6) versus a) PI, b) FC, c) $D_{50}$, and d) $C_{u}$ 
a)

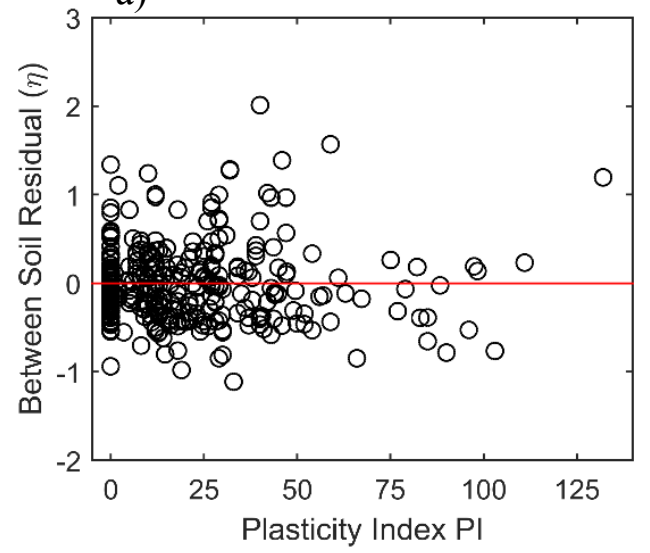

c)

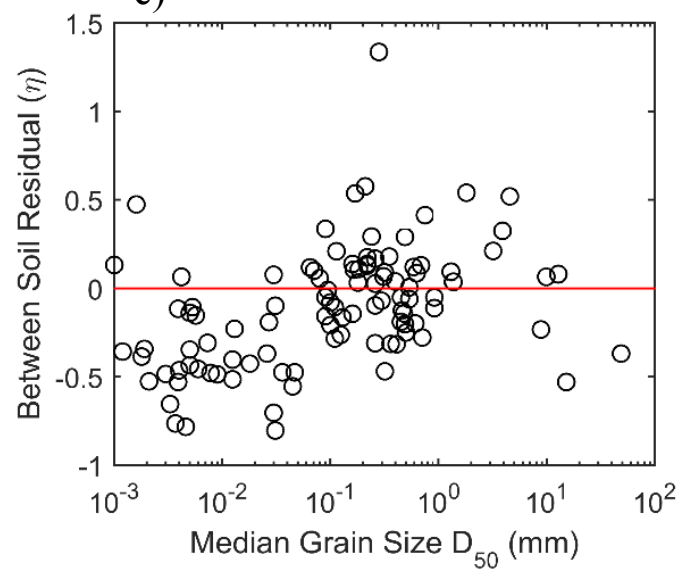

b)

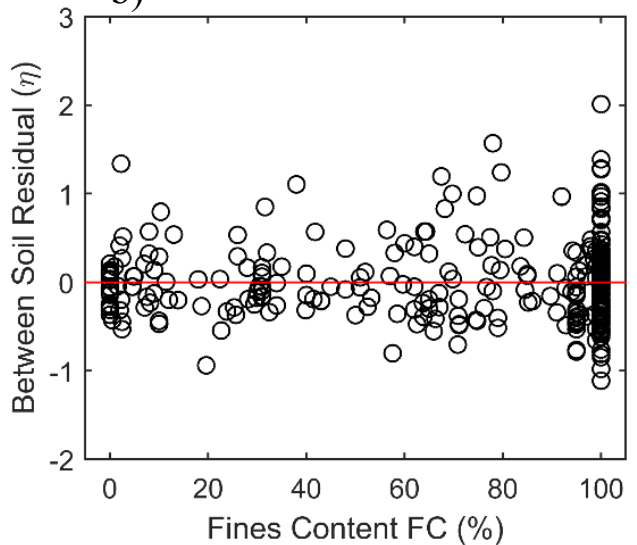

d)

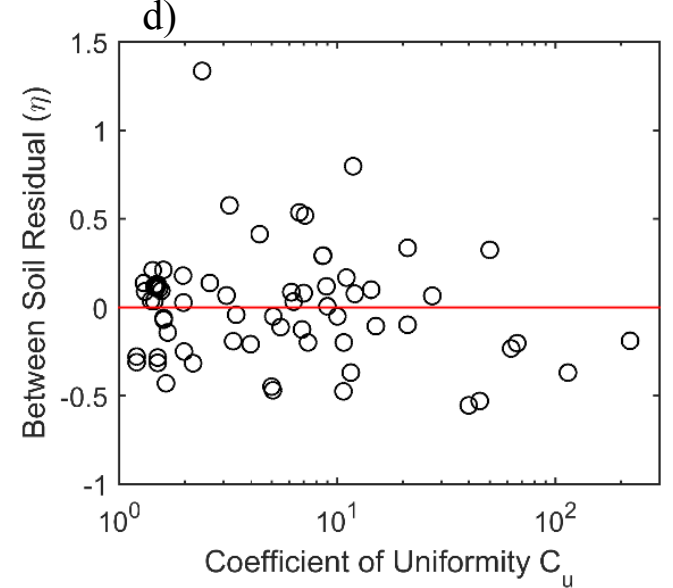

Figure 5. Between soil residuals $\eta$ for equation (11) versus a) PI, b) FC, c) $D_{50}$, and d) $C_{u}$

Table 3. Value of coefficient $\mathrm{c}_{1}$ regressed for equation (3) (only soils with $\sigma^{\prime} \mathrm{m}=1$ atmosphere and $\mathrm{OCR}=1$ ); equation (4) (only tests with $\mathrm{OCR}=1$ ), and equations (6) and (11) (all tests in the database)

\begin{tabular}{ccc}
\hline Equation \# & $\mathrm{c}_{1}$ & Standard Error \\
\hline 3 & 408.6 & 20.19 \\
4 & 444.9 & 13.89 \\
6 & 457.1 & 41.8 \\
11 & 790.2 & 15.85 \\
\hline
\end{tabular}

Table 4. Evaluation of the different $G_{\text {max,lab }}$ models (using all soils in the database)

\begin{tabular}{cccccc}
\hline $\begin{array}{c}\text { Equation } \\
\text { No. }\end{array}$ & $\phi$ & $\tau$ & $\sigma$ & $\begin{array}{c}\text { Models } \\
\text { compared }\end{array}$ & p-value \\
\hline 3 & 0.414 & 0.638 & 0.761 & - & \\
4 & 0.135 & 0.516 & 0.534 & 4 vs. 3 & $<0.001$ \\
6 & 0.130 & 0.456 & 0.474 & 6 vs. 4 & $<0.001$ \\
10 & 0.130 & 0.438 & 0.457 & 10 vs. 6 & 0.930 \\
11 & 0.130 & 0.438 & 0.457 & 11 vs. 6 & 0.004 \\
\hline
\end{tabular}


Table 5. Data used to develop the $G_{\text {max,insitu model }}$

\begin{tabular}{cccc}
\hline Reference & Lab Test $^{\mathrm{a}}$ & Field Test $^{\mathrm{b}}$ & Soil(s) Tested \\
\hline Cavallaro et al. 2000 & RC, TS & DH & Fabriano Clay \\
EPRI 1994 & RC & CH,DH,SL & Soils from California and Taiwan \\
Lefebvre et al. 1994 & RC & SASW & Champlain Clay \\
Nigbor 2012 (ROSRINE) & RC & SL & Soils from California \\
Schneider et al. 1999 & RC & SASW & Piedmont Residual Soils \\
\hline${ }^{\text {a }}$ RC = resonant column; TS = torsional shear & & \\
${ }^{\mathrm{b}} \mathrm{CH}=$ crosshole; DH = downhole; SASW = spectral analysis of surface waves; SL = suspension logger
\end{tabular}

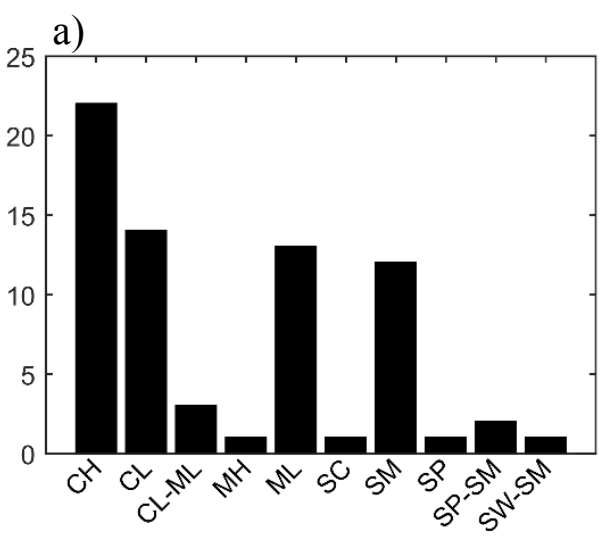

USCS Classification

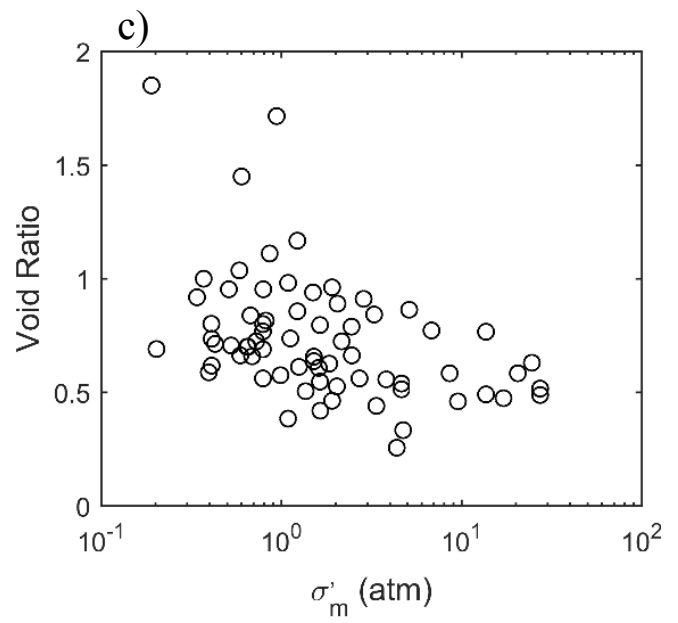

b)

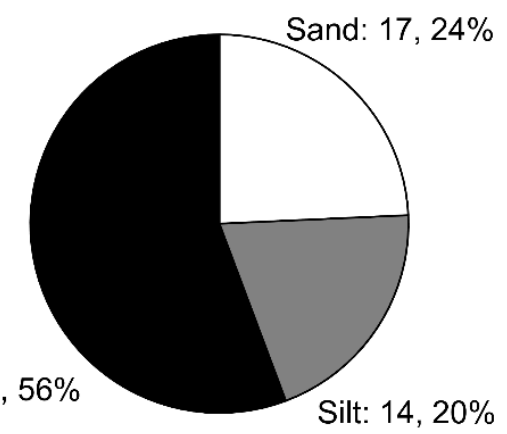

d)

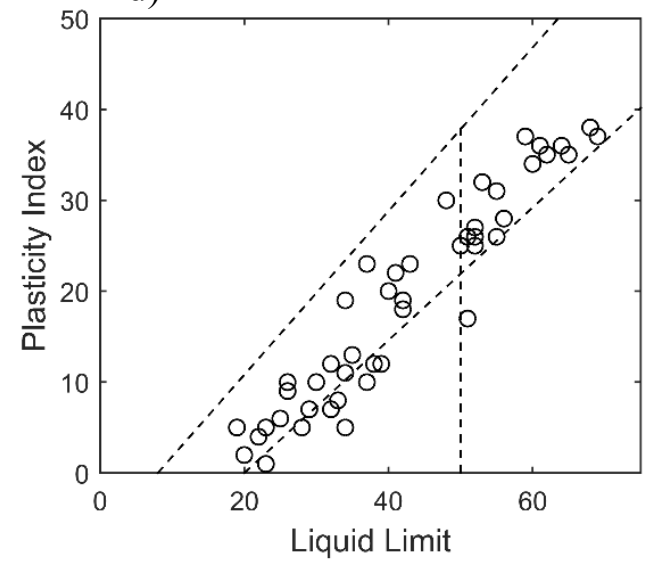

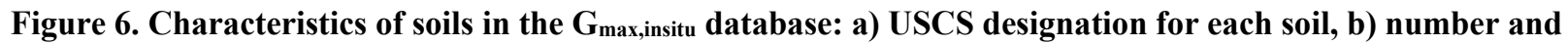
percentage of tests for each general soil type, c) distribution of void ratio and $\sigma_{\mathrm{m}}$ for all tests, and d) plasticity characteristics of cohesive soils 
a)

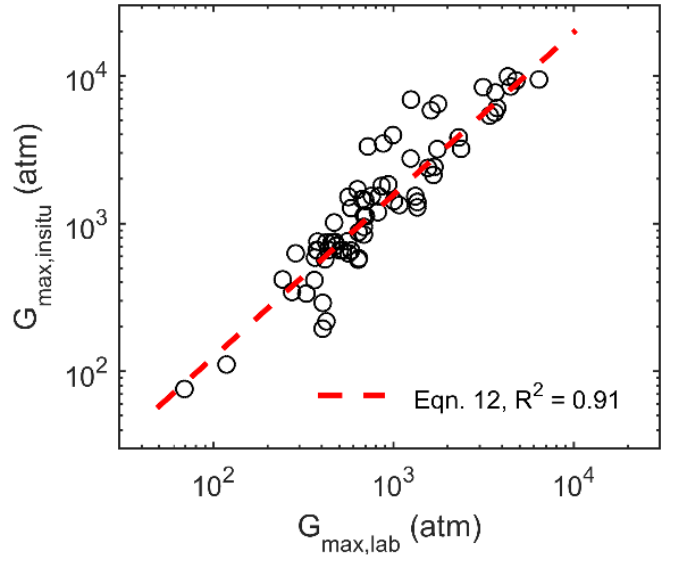

c)

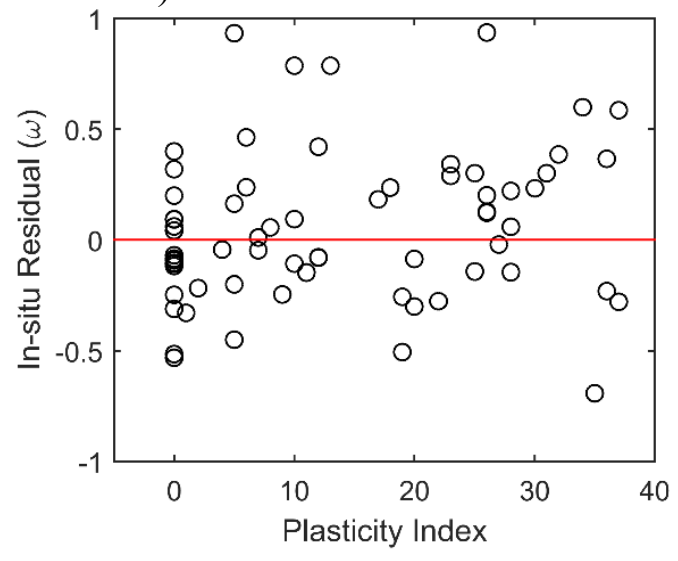

b)

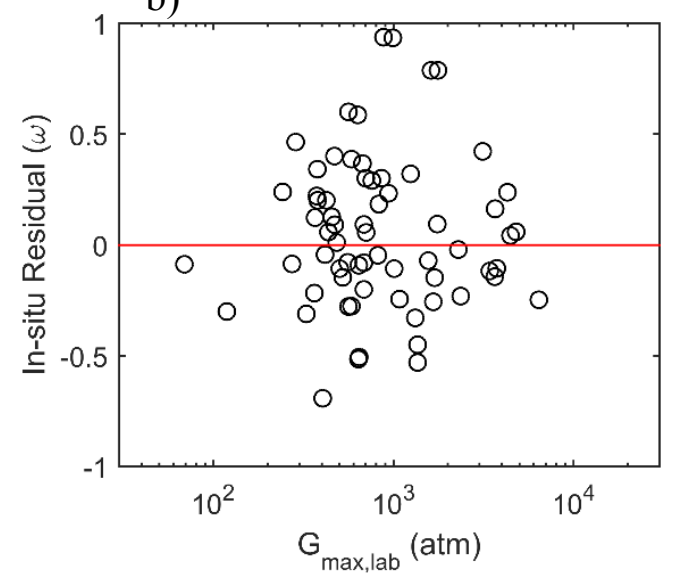

d)

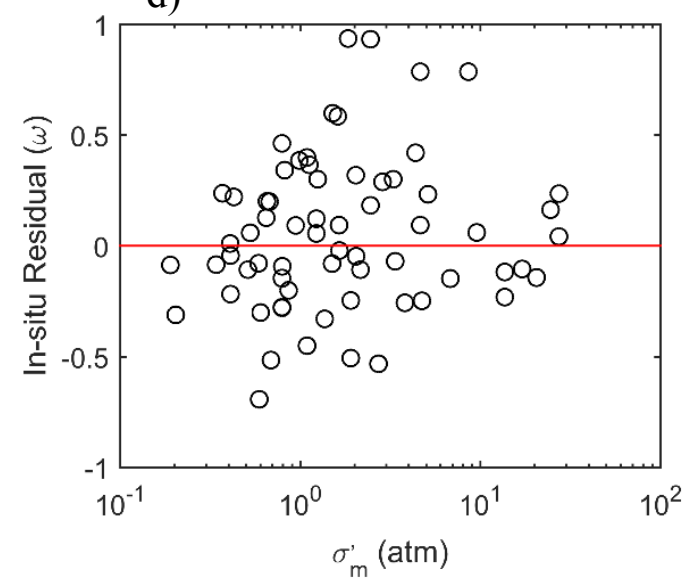

Figure 7. Results of the regression for the $G_{\text {max,insitu model }}$

Table 6. Data used to validate the $\mathbf{G}_{\text {max,insitu model }}$

\begin{tabular}{ccc}
\hline Reference & Field Test $^{\mathrm{a}}$ & Soil(s) Tested \\
\hline EPRI 1994 & CH,DH,SL & Soils from California and Taiwan \\
Lefebvre et al. 1994 & SASW & Champlain Clay \\
Nikolaou 2012 & CH & Soils from New York City \\
Nigbor 2012 (ROSRINE) & SL & Soils from California \\
Pass 1991 & CH & Soils from Treasure Island, CA \\
Schneider et al. 1999 & SASW & Piedmont Residual Soils \\
Shibuya and Tanaka 1996 & SCPT & Various Japanese Clays \\
\hline
\end{tabular}

${ }^{a} \mathrm{CH}=$ crosshole; $\mathrm{DH}=$ downhole; $\mathrm{SASW}=$ spectral analysis of surface waves; $\mathrm{SL}=$ suspension logger; $\mathrm{SCPT}=$ seismic cone penetration test 

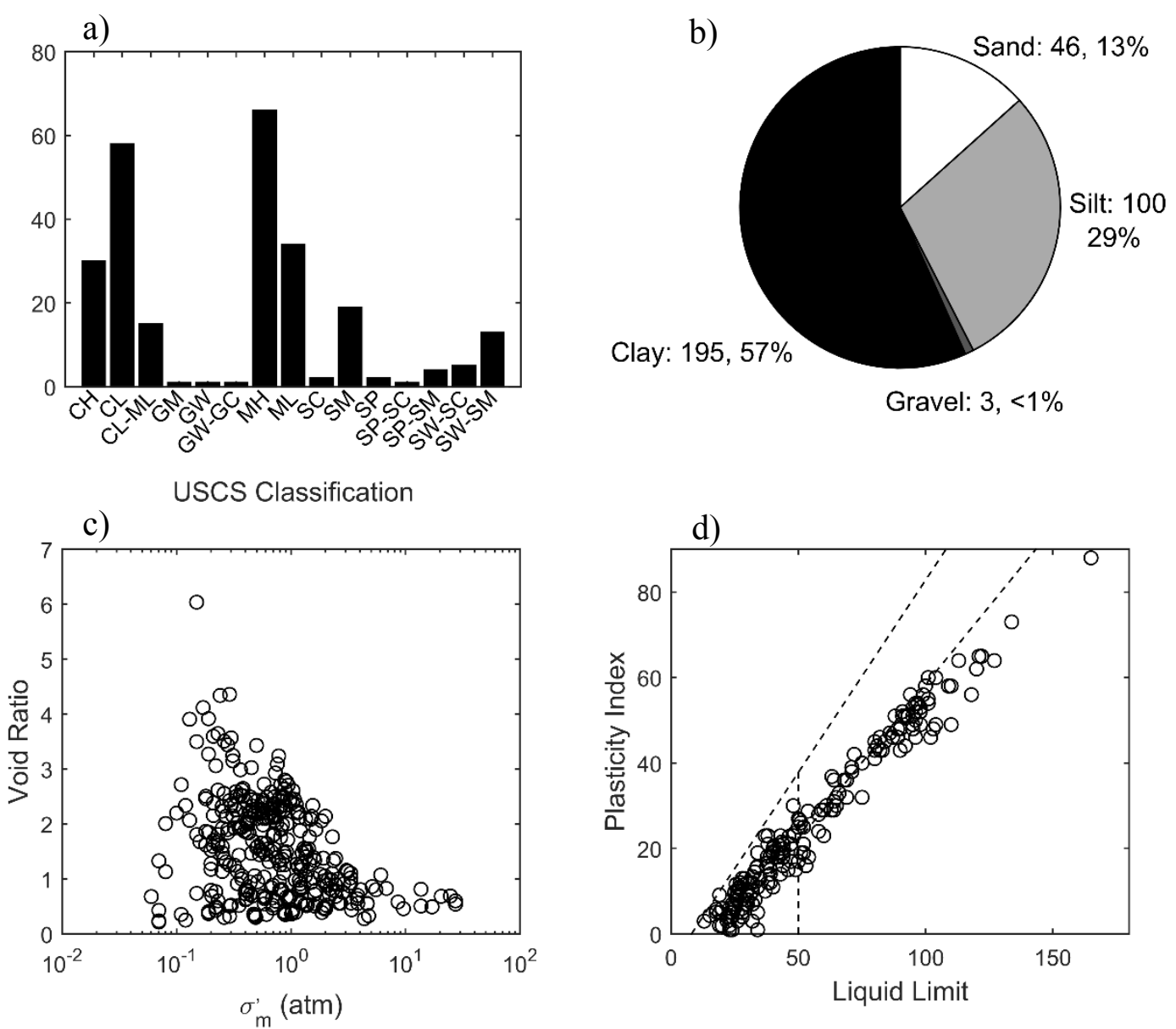

Figure 8. Characteristics of soils in the validation database: a) USCS designation for each soil, b) number and percentage of tests for each general soil type, c) distribution of void ratio and $\sigma^{\prime} \mathrm{m}$ for all tests, and d) plasticity characteristics of cohesive soils

Table 7. Comparison of models (in natural log units)

\begin{tabular}{|c|c|c|c|c|c|c|}
\hline & & $\begin{array}{l}\text { Present } \\
\text { Study }\end{array}$ & $\begin{array}{l}\text { Jamiolkowski } \\
\text { et al. (1991) }\end{array}$ & $\begin{array}{l}\text { Hardin } \\
(1978)\end{array}$ & $\begin{array}{c}\text { Kokusho } \\
\text { et al. } \\
\text { (1982) }\end{array}$ & $\begin{array}{l}\text { Kallioglou } \\
\text { et al. } \\
\text { (2008) }\end{array}$ \\
\hline \multirow{3}{*}{$\begin{array}{l}\stackrel{n}{\overline{0}} \\
\mathscr{n} \\
\bar{Z}\end{array}$} & Mean & -0.03 & -0.33 & -0.11 & & \\
\hline & Median & -0.12 & -0.43 & -0.15 & n.a. & n.a. \\
\hline & $\sigma_{\text {total }}$ & 0.43 & 0.46 & 0.47 & & \\
\hline \multirow{3}{*}{ 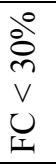 } & Mean & 0.03 & 0.00 & 0.26 & & \\
\hline & Median & 0.06 & -0.02 & 0.31 & n.a. & n.a. \\
\hline & $\sigma_{\text {total }}$ & 0.63 & 0.68 & 0.63 & & \\
\hline \multirow{3}{*}{ 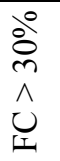 } & Mean & -0.04 & -0.35 & -0.13 & 0.51 & 0.34 \\
\hline & Median & -0.12 & -0.44 & -0.16 & 0.38 & 0.30 \\
\hline & $\sigma_{\text {total }}$ & 0.41 & 0.43 & 0.44 & 0.60 & 0.60 \\
\hline
\end{tabular}

